maximum numbers in early adulthood and decline thereafter. Gallagher et al studied 913 schoolchildren in western Canada and reported that large numbers of naevi in children aged 6 and over are found in fair skinned children who have a history of burning sunburn. ${ }^{4}$ The children in our study did not have a history of severe sunburn

The significance of such high naevus counts in these children is not yet established. Studies from the west of Scotland, ${ }^{5}$ Scandinavia,${ }^{6}$ and the west coast of America have all established that large numbers of banal naevi are the strongest risk factors for subsequent development of malignant melanoma. In the west of Scotland the three next most important risk factors, in descending order of importance, are a freckling tendency, clinically atypical naevi (greater than $5 \mathrm{~mm}$ and with an irregular edge, irregular pigment, or inflammation), and a history of episodes of severe blistering sunburn.

It is important to emphasise that not all melanomas develop on these pre-existing naevi but that it is speculated that factors which give rise to melanoma are also risk factors for naevi.

Though we know that children treated in childhood for malignancies with chemotherapy are at risk of developing second malignancies, malignant melanoma is not at present recognised as such a second malignancy. Long term follow up of these children already occurs, and it is recommended that they should have periodic skin examinations. In addition, advice should be given to both parents and children on the clinical appearance of early melanoma and on avoiding excessive sun exposure and in particular frank sunburn.

We are grateful to Dr Brenda Gibson, of the Royal Hospital for Sick Children, Glasgow, for allowing us to study these children.

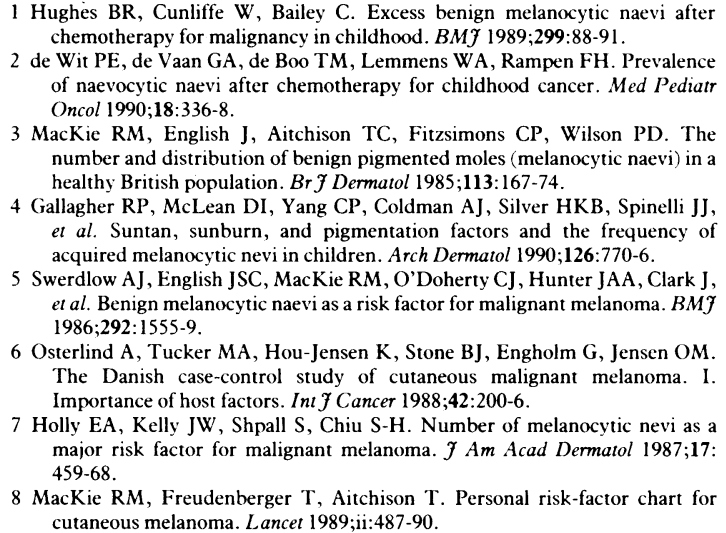
chemotherapy for malignancy in childhood. BMF 1989;299:88-91.

2 de Wit PE, de Vaan GA, de Boo TM, Lemmens WA, Rampen FH. Prevalence of naevocytic naevi after chemotherapy for childhood cancer. Med Pediatr

3 MacKie RM, English J, Aitchison TC, Fitzsimons CP, Wilson PD. The number and distribution of benign pigmented moles (melanocytic naevi) in a healthy British population. Br f Dermatol 1985;113:167-74

4 Gallagher RP, McLean DI, Yang CP, Coldman AJ, Silver HKB, Spinelli JJ, et al. Suntan, sunburn, and pigmentation factors and the frequency of acquired melanocytic nevi in children. Arch Dermatol 1990;126:770-6.

5 Swerdlow AJ, English JSC, MacKie RM, O'Doherty CJ, Hunter JAA, Clark J, et al. Benign melanocytic naevi as a risk factor for malignant melanoma. $B M \mathcal{F}$ 1986;292:1555-9.

6 Osterlind A, Tucker MA, Hou-Jensen K, Stone BJ, Engholm G, Jensen OM. The Danish case-control study of cutaneous malignant melanoma. I. Importance of host factors. Int f Cancer 1988;42:200-6.

7 Holly EA, Kelly JW, Shpall S, Chiu S-H. Number of melanocytic nevi as a major risk factor for malignant melanoma. $\mathcal{F}$ Am Acad Dermatol 1987;17: 459-68.

8 MacKie RM, Freudenberger T, Aitchison T. Personal risk-factor chart for cutaneous melanoma. Lancet 1989;ii:487-90.

(Accepted 11 August 1992)

\title{
Female streetworking prostitution and HIV infection in Glasgow
}

\author{
Neil McKeganey, Marina Barnard, Alastair Leyland, Isobel Coote, Edward Follet
}

Public Health Research Unit, University of Glasgow, Glasgow G12 8RZ

Neil McKeganey, senior research fellow

Marina Barnard, research fellow

Alastair Leyland, statistician

Hepatitis/HIV Reference Laboratory, Regional Virus Laboratory, Ruchill Hospital, Glasgow

Isobel Coote, research technician

Edward Follet, head

Correspondence to: Dr McKeganey.

BMF 1992;305:801-4

\section{Abstract}

Objectives-To identify the extent of HIV infection and injecting drug use among female streetworking prostitutes in Glasgow; to estimate the size of the female streetworking prostitute population in the city; and to estimate the number of HIV positive women working as prostitutes on the streets in Glasgow.

Design-Observation and interviewing of female prostitutes over seven months in red light district; analysis of saliva samples for presence of antibodies to HIV; capture-recapture approach to estimating the size of the female streetworking prostitute population.

Setting-Glasgow.

Subjects-206 female streetworking prostitutes.

Main outcome measures-Number of women with antibodies to HIV, self reported use of injecting drugs, history of contact with 206 women.

Results-Saliva samples were requested from 197 women; $159(81 \%)$ provided samples. Four $(2 \cdot 5 \%$, $95 \%$ confidence interval $0 \cdot 7 \%-6 \cdot 3 \%$ ) of the samples were positive for $\mathrm{HIV}$, all of which had been provided by women who injected drugs. Of the 206 streetworking women contacted $147(71 \%)$ were injecting drug users. About 1150 women are estimated to work on the streets in Glasgow over a 12 month period.

Conclusions-HIV is not as widespread among female prostitutes as many reports in the tabloid press suggest. A greater proportion of female streetworking prostitutes in Glasgow are injecting drugs than has been reported for other British cities.

\section{Introduction}

Female prostitutes have often been presented as a major source of HIV infection. This image derives in large part from the situation in certain countries in sub-
Saharan Africa, where prostitution has undoubtedly played a key role in the heterosexual transmission of HIV infection. ' There are obvious dangers in extrapolating from what may be happening in one area to what may be happening in another, especially when the areas in question are different in virtually every respect. HIV seroprevalence studies of female prostitutes in Europe and North America, for example, have rarely identified a prevalence of HIV in excess of $5 \% .^{2}$ This figure has tended to be higher when the women surveyed were prostitutes and injecting drugs. ${ }^{3}$

We report on the prevalence of HIV infection among a sample of female streetworking prostitutes in Glasgow and on the extent of injecting drug use among such women. We also estimate the size of the female streetworking prostitute population in Glasgow and the total number of HIV positive female prostitutes working on the streets in the city.

\section{Methods}

From January 1991 to September 1991 the main authors of this paper (NM and MB) carried out fieldwork on 53 nights (a total of more than 156 hours) in Glasgow's main red light area. This work was organised in accordance with strict time sampling procedures covering every day of the week and the times of day prostitute women were observed working (approximately 8 pm to $2 \mathrm{am}$ ). By spreading the data collection over seven months we sought to reduce any bias associated with seasonal variations in working.

Fieldwork for this study entailed the researchers repeatedly walking around the entire set of streets comprising the red light area in the city and approaching as many women as possible during each two hour fieldwork period. We were consistently able to contact about $90 \%$ of all women seen working during each fieldwork period. Although all of these women spend a 
proportion of each night away from the streets, in clients' cars or flats, they nevertheless return to the area repeatedly during their evening's work. Although several saunas and massage parlours operate within the red light area, this study relates solely to women working on the streets. With the agreement of the Greater Glasgow Health Board all women contacted in this study were offered a range of condoms, sterile injecting equipment, and an advice leaflet on HIV risk reduction which included the telephone numbers of local agencies. We contacted an average of 21.6 women each night; in total 206 women were contacted over the 53 nights of fieldwork.

Short street interviews were carried out with the women, covering those aspects of their work and their private lives that might be associated with the spread of HIV infection. Where women requested sterile injecting equipment these interviews also concentrated on establishing that it was the woman rather than her partner who was injecting; for example, women were asked about which drugs they were using and which parts of their body they were injecting into. The women were also asked to provide an anonymous saliva sample. This was tested, with their informed consent, for the presence of antibodies to HIV. Test samples were marked with a unique identifier to avoid repeat testing of the same women during the study period. Test results were provided only to a member of the research team who was not in contact with the women so that the confidentiality of test results could be maintained. Saliva samples were analysed for antibodies to HIV-1 and HIV-2 using an immunoglobin A antibody capture enzyme linked immunosorbent assay (ELISA).+ Samples that were repeatedly reactive in this test were further analysed by a modified western blot procedure. ${ }^{5}$ Samples were considered positive for HIV antibody if they showed bands representing reactivity against one or more gag or pol genes and one of the env genes.

To estimate the size of the female streetworking prostitute population in Glasgow we used a variant of the capture-recapture approach. The value of capturerecapture approaches in estimating the prevalences of non-communicable diseases has recently been much discussed. ${ }^{6-8}$ We have refined a method based on maximum likelihood ${ }^{9}{ }^{10}$ along the lines of the log-linear models proposed by Cormack. ${ }^{11}$ We have described our statistical analyses in detail elsewhere. ${ }^{12}$

Data collection consisted of keeping a detailed record of the total number of women seen working over a two hour period during each night of fieldwork, as well as the number of women spoken to directly. Unique identifiers were recorded for each woman (consisting of initials and first two parts of their date of birth) after each contact. Thus the "capture history" of each woman was available to us - an exact record of which nights each woman was seen to be working and hence of which nights she was not seen. The frequency with which women were seen over the period of fieldwork as well as the rate at which women were contacted for the first time allowed us to estimate the size of the female streetworking prostitute population in the city. By combining our estimate of the size of the female streetworking prostitute population in Glasgow with our estimate of the prevalence of HIV infection among such women we could estimate the number of HIV positive female prostitutes working on the streets in Glasgow.

\section{Results}

\section{PREVALENCE OF HIV INFECTION}

Any attempt to assess the role played by prostitutes in the spread of HIV infection must first establish the prevalence of $\mathrm{HIV}$ infection in this population. Of the
206 women contacted in this study, nine women were seen only before saliva testing began. Twelve women declined to provide a test sample, and 26 women were seen so infrequently that the researchers were unable to request a test sample. Test samples were obtained from 159 women-a success rate of $81 \%$. There is no evidence of systematic bias in those women tested. Similar proportions of women who did and did not inject drugs, for example, were present in both groups of women.

The low prevalence of HIV $-2 \cdot 5 \%$ overall (table)is encouraging. It is striking that all women positive for HIV whom we identified were injecting drug users. HIV may have been transmitted by sharing needles and syringes rather than through commercial or non-commercial sex. These data are in agreement with other studies in Europe that have identified a higher prevalence of HIV infection in female prostitutes who injected drugs than in those who did not. ${ }^{3}$

Prevalence of HIV infection among female street prostitutes

\begin{tabular}{lccc}
\hline & All women & Drug injectors & Non-injectors \\
\hline No of women tested & 159 & 115 & 44 \\
No of women positive & 4 & 4 & 0 \\
$\begin{array}{l}\text { Proportion of HIV positive } \\
\quad \text { women }\end{array}$ & $2 \cdot 5 \%$ & $3 \cdot 5 \%$ & $0 \%$ \\
$95 \%$ Confidence interval & $0 \cdot 7 \%$ to $6 \cdot 3 \%$ & $1 \cdot 0 \%$ to $8 \cdot 7 \%$ & $0 \%$ to $6.6 \%$ \\
\hline
\end{tabular}

\section{EXTENT OF INJECTING DRUG USE}

Previous studies in the United Kingdom have identified appreciable numbers of female prostitutes injecting drugs. Kinnell reported a figure of $15 \%$ in Birmingham, ${ }^{13}$ Day et al reported $14 \%$ in London ${ }^{2}$ and Morgan-Thomas et al reported $20 \%$ for Edinburgh. ${ }^{14}$ We found that within Glasgow a much greater number of female streetworking prostitutes were injecting drugs than has been reported for other cities in the United Kingdom. Of the 206 streetworking women contacted in this study, $147(71 \%)$ injected drugs. These 206 women resulted in a total of 1145 contacts, each woman being contacted an average of 5.6 times. Of these contacts, $805(70 \%)$ were with women injecting drugs. That there were similar proportions of women who did and did not use injecting drugs in both the total number of women contacted and in the total number of times the 206 women were contacted suggests that the drug injecting and non-drug injecting women had a similar frequency of working.

\section{EXTENT OF FEMALE STREET PROSTITUTION IN GLASGOW}

To predict the prevalence of HIV and AIDS it is clearly important to have an idea of the actual number of people positive for HIV within a given area or associated with particular risk activities. Although we identified $2 \cdot 5 \%$ of streetworking female prostitutes as HIV positive, the actual number of HIV positive female prostitutes working on the streets of Glasgow can be estimated only if we can also estimate the overall size of the female streetworking prostitute population in the city.

Cormack has detailed a method of analysis for identifying not only the extent to which there may be both migration into a population and emigration from a population but also the existence of heterogeneity within a population. "In our case heterogeneity refers to the fact that different women will have a different likelihood of working on a given night. This is important because any assumption of population homogeneity will underestimate the size of a heterogeneous population.

Our capture-recapture data on the women give overwhelming evidence of an open population $(\mathrm{p}<0.0001$ throughout the study period). Adjusting the population estimates as a response to the inherent 
heterogeneity suggests that the women seen working on any one night are a sample drawn from a population of about 200 . Over the study period this population consistently changed at an average rate of about $8 \%$ (19 women a week); the approximate equality of the immigration and emigration processes meant that the population size remained fairly constant - that is, there seemed to be no seasonal fluctuations. Combining the above figures, we would expect there to be about 1150 streetworking prostitutes in the city over a 12 month period. There is also support for a pattern of women moving into and out of prostitution over a relatively short period. There is little evidence of women ceasing prostitution in Glasgow and moving to work in other cities. ${ }^{15}$

On the basis of the proportion of women who tested HIV positive given in the table we estimate that there are five HIV positive women working on the streets in Glasgow at any one time; during the course of a year we would expect about 29 of the women working to be HIV positive. The extrapolation of the sample tested for HIV to the population estimates assumes that the frequency of working is the same for the HIV positive and HIV negative women and that the sample tested is representative of the population. The small number of HIV positive women in the sample precludes any meaningful comparison of the frequency of working of our contacts in the two groups.

\section{RISK BEHAVIOUR AND RISK REDUCTION}

Only a few women interviewed reported sharing injecting equipment. Many women pointed out that although they had shared in the past there was now no longer a need to do so given that they were provided with sterile injecting equipment by a street level, drop in clinic operating within the red light area as well as by the network of needle exchange clinics operating within Glasgow. The fact that HIV had such a low prevalence among the women is perhaps as good an indication as any that sharing of injecting equipment was not widespread among streetworking female prostitutes.

Condoms were reported as being universally used for vaginal sex, oral sex, and often for the masturbation of clients. Only two of the women interviewed reported having provided anal sex in the distant past, and both had resolved to discontinue this service.

\section{Discussion}

The low prevalence of HIV infection identified in this study is encouraging. What is much less encouraging, however, is the substantial number of streetworking female prostitutes in Glasgow who inject drugs. There may be several reasons why we have identified a greater proportion of women injecting drugs than has been reported for other cities in Britain. Firstly, our study has concentrated only on streetworking women. Most of the prostitution studies in the United Kingdom have shown higher levels of risk behaviour (including use of injecting drugs) among streetworking women than among non-streetworking women. Secondly, by offering female prostitutes sterile injecting equipment we are likely to have identified instances of drug injecting that would have been concealed from us in other circumstances. All of the women we contacted were continually liable to arrest while working; it is unlikely that women who were not injecting would have been requesting injecting equipment from us, with the risk of being found in possession of injecting equipment by either the police or clients. Thirdly, we know that Glasgow has a large population of injecting drug users-the most recent estimate places the figure at around 9500 people. ${ }^{16}$ This represents an overall prevalence of $15 \cdot 0 / 1000$ population aged $15-55$ in Glasgow, $8 \cdot 3 / 1000$ women in this age group.

There is a need for caution in interpreting the reports of widespread use of condoms and the lack of reports of anal sex. Our interviews were conducted within the red light area, and a strong occupational culture shared by the women may have inhibited their reporting of those occasions when condoms were not used or when anal sex was provided. Despite this, prostitutes reported that clients continue to offer additional money for unprotected sex, that condoms burst, and that some clients deliberately attempt to remove condoms during sex. These women have also provided us with frequent reports of physical intimidation and rape which could be associated with unsafe sex. From our observations within the red light area it was apparent that a minority of women were working in a very confused state as a result of recent drug use and may not have been able to insist on condoms being worn. Despite such indications, our impression is that a condom is used during most commercial sex. There is a need, however, for more detailed information on this important area.

\section{Conclusion}

The low prevalence of HIV infection among female streetworking prostitutes identified in this study should serve as a strong counterweight to characterisations of female prostitutes as a major reservoir of HIV infection. Our prevalence estimate of $2 \cdot 5 \%$ is particularly striking given the large proportion of streetworking women injecting drugs in Glasgow. We estimate that there may be about $29 \mathrm{HIV}$ positive women working on the streets of Glasgow over a 12 month period. A small number of HIV positive female prostitutes would not necessarily lead to further spread of the virus if condoms were always used. Although it is difficult to collect reliable and valid information on condom use, it is our impression from interviews with the women that during most commercial sex in Glasgow a condom is used.

The fact that all of the HIV positive female prostitutes were injecting drug users is important. We know from other studies that shortages in the availability of sterile injecting equipment can increase equipment sharing within social networks of injecting drug users. The limited spread of HIV among the prostitutes who used injecting drugs in Glasgow is probably a good indication that injecting equipment was shared only occasionally. Glasgow is undoubtedly fortunate in that streetworking female prostitutes in the city are provided with condoms, general health care, and sterile injecting equipment by a drop in clinic operating within the red light area. This facility is attended by many of the prostitutes working in the area. There is a case for similar services to be provided in other areas where equivalent services do not exist.

We are grateful to all of the women who agreed to take part in this research. We would also like to acknowledge the help of Professor R Cormack in applying mark recapture ideas to our work. For assistance throughout our research we would like to thank Dr Michael Bloor, Dr Susan Carr, Dr Laurence Gruer, Dr Alison Mack, and representatives of Strathclyde Regional Police. This study is funded by the Medical Research Council. The Public Health Research Unit is funded by the Chief Scientist Office of the Scottish Office Home and Health Department and the Greater Glasgow Health Board. The opinions expressed in this paper are not necessarily those of the Scottish Home and Health Department.

1 Cameron W. Identification of biological co-factors in heterosexual transmission of HIV infection: epidemiologic observation and intervention in Nairobi, Kenya. In: Alexander N, Gabelnick H, Speider J, eds. Heterosexual transmission of AIDS. New York: Wiley-Liss, 1990. 
2 Day S, Ward H, Harris JRW. Prostitute women and public health. BMF 1988;297:1585

3 Tirelli U, Rezza G, Guiliani M, Caprilli F, Gentilli G, Lazzarin A, et al. HIV seroprevalence among 304 female prostitutes from four Italian towns. AIDS 1989;3:547-8

4 Parry J, Perry K, Mortimer P. Sensitive assays for viral antibodies in saliva: an alternative to tests on serum. Lancet 1987;ii:72-5.

5 Tappin DM, Girdwood WA, Follet EAC, Kennedy R, Brown AJ, Cockburn F. Prevalence of maternal infection in Scotland using an unlinked anonymous testing of newborn babies. Lancet 1991;337:1565-7.

6 LePorte RE, McCarty DJ, Tull ES, Tajima N. Counting birds, bees, and NCDs. Lancet 1992;339:494-5.

7 Hook EB, Regal RR. Capture-recapture methods. Lancet 1992;339:742.

8 Frischer $M$, Leyland AH. Reliability of population and prevalence estimates. Lancet 1992;339:995.

9 McKeganey NP, Barnard MA, Bloor MJ, Leyland AH. Injecting drug use and female streetworking prostitution in Glasgow. AIDS 1990;4:1153-5.

10 Bloor MJ, Leyland AH, Barnard MA, McKeganey NP. Estimating hidden populations: a new method of calculating the prevalence of drug injecting and non-injecting female prostitutes. Br f Addiction 1991;86:1477-83.
11 Cormack RM Log-linear models for capture-recapture. Biometrics 1989:45: $395-413$

12 Leyland AH, Barnard M, McKeganey N. The use of capture recaptur methodology to estimate and describe covert populations: an application to female streetworking prostitution in Glasgow. Paper presented to the International Conference on Social Science Methodology, University of Trento, Italy, 22-26 June 1992.

$13 \mathrm{Kinnell} \mathrm{H.} \mathrm{Prostitutes,} \mathrm{their} \mathrm{clients} \mathrm{and} \mathrm{risks} \mathrm{of} \mathrm{HIV} \mathrm{infection} \mathrm{in} \mathrm{Birmingham}$ Birmingham: Dept of Public Health Medicine, 1989. (Occasional paper.)

14 Morgan Thomas R, Plant MA, Plant MC, Sales DI. Risks of AIDS amon workers in the sex industry: Some initial results from a Scottish study. $B M \mathcal{F}$ 1989;299:148-9.

15 McKeganey NP, Barnard MA. Selling sex: female street prostitution and HIV related risk behaviour in Glasgow. AIDS Care (in press).

16 Frischer M, Bloor M, Finlay A, Goldberg D, Green S, Haw S, et al. A new method of estimating the prevalence of iniecting drug use in an urban population: results from a Scottish city. Int f E pidemiol 1991;20:997-1000.

(Accepted 3 September 1992)

\title{
Computer system for assisting with clinical interpretation of tumour marker data
}

\author{
M S Leaning, S Gallivan, E S Newlands, J Dent, M Brampton, D B Smith, K D Bagshawe
}

\section{Clinical Operational \\ Research Unit, Department of Statistical Science, University College London, London WC1E 6BT \\ M S Leaning, principal research fellow \\ $\mathrm{S}$ Gallivan, principal research fellow}

Department of Medical Oncology, Charing Cross Hospital, London W6 8RF E S Newlands, professor of cancer medicine J Dent, research officer M Brampton, data manager D B Smith, senior registrar K D Bagshawe, emeritus professor of oncology

Correspondence to: Dr Leaning.

\section{Abstract}

Objective-To design and evaluate a computer advisory system for the treatment of gestational trophoblastic tumour.

Design-A comparison of clinicians' treatment decisions with those of the computer system. Two datasets were used: one to calibrate the system and one to independently evaluate it.

Setting-Department of medical oncology.

Patients-Computerised records of 290 patients with low risk gestational trophoblastic tumour for whom the advisory system could predict the adequacy of treatment. The calibration set comprised patients admitted during 1979-86 (227) and the test set patients during 1986-89 (63).

Main outcome measures-The system's accuracy in predicting need to change treatment compared with clinicians' actions. The mean time faster that the system was in predicting the need to change treatment.

Results -On the calibration dataset the system was $94 \%(164 / 174)$ accurate in predicting patients whose treatment was adequate, recommending change when none occurred in only $10(6 \%)$ patients. In patients whose treatment was changed the system recommended change earlier than clinicians in 39/53 cases $(74 \%)$, with a mean time advantage of 14.9 (SE $2 \cdot 02$ ) days. On the test dataset the system had an accuracy of $91 \%(31 / 34)$ in predicting treatment adequacy and a false positive rate of $9 \%(3 / 34)$. The system recommended change earlier than clinicians in $22 / 29$ cases $(76 \%)$, with a mean time advantage of $12 \cdot 5(2 \cdot 22)$ days.

Conclusions-The computer advisory system could improve patient management by reducing the time spent receiving ineffective treatment. This has implications for both patient time and clinical costs.

\section{Introduction}

Serial measurements of serum human chorionic gonadotrophin are central to the management of patients with gestational trophoblastic tumour. ${ }^{1}$ Serum human chorionic gonadotrophin concentration is monitored before, during, and after cytotoxic chemotherapy to assess tumour growth and the response to treatment. During successful treatment, human chorionic gonadotrophin concentrations decrease rapidly. If, however, treatment becomes ineffective the concentration will fall more slowly, plateau, or rise. It is important to detect drug resistance as soon as possible and to modify the patient's treatment appropriately.

In a preliminary analysis we examined human chorionic gonadotrophin concentration during treatment in $\mathbf{3 4 0}$ low risk patients with gestational trophoblastic tumour attending the department of medical oncology at Charing Cross Hospital during 1979-86. Two groups of patients were distinguished: those who responded successfully to one treatment and those who needed to change treatment because of drug resistance (two treatment group). Patients whose treatment was changed because of toxicity were excluded. Mean initial human chorionic gonadotrophin concentrations at the start of treatment and mean initial regression slopes were significantly different $(p<0.002)$ for the two groups, but this difference was not sufficient to discriminate accurately between the two groups. A linear discriminant analysis using initial human chorionic gonadotrophin concentration and initial regression slope as factors produced a $33.9 \%$ false positive rate (one treatment patients assigned to the two treatment group) and a $31 \cdot 7 \%$ false negative rate (two treatment patients assigned to the one treatment group). We concluded that continuous monitoring of serum human chorionic gonadotrophin was necessary during treatment.

Even with regular measurements of human chorionic gonadotrophin during treatment interpreting the marker response can be difficult, despite routine graphical display of the data on a computer system. This paper describes the design and evaluation of a computer advisory system (MARKER) intended to improve the management of low risk gestational trophoblastic tumour. The aim of this system is to allow a clinician to detect an inadequate treatment response as soon as possible. This is done by forecasting the trend of the human chorionic gonadotrophin concentration and comparing the predicted time to basal concentration $(<5 \mathrm{IU} / \mathrm{l})$ with an expected distribution of times derived from a database of past cases.

This approach may also be applicable to other cancers with serum markers, in particular to germ cell tumours and ovarian cancer. The general principle underlying the approach to computer assisted treatment monitoring is that a formal algorithm is used to 